\title{
General Motors: The Electric Revolution
}

Sharon L. Poczter, Cornell University, USA

Luka M. Jankovic, Cornell University, USA

\begin{abstract}
The recent explosion in demand for electric vehicles, fueled by both increasing gas prices and rising awareness of consumers to environmental concerns, has challenged traditional car manufacturers to explore alternatives to gas-powered automobiles. Of the new models presenting alternatives to traditional gas-powered cars, the award-winning Tesla Model S and Nissan Leaf have commanded the majority of the attention and sales in the electric car market. General Motors' Volt, on the other hand, has seen lukewarm sales after missing its high production and consumption expectations. As the inevitable pursuit of sustainable solutions for energy use continues, GM is placed in a precarious situation. On the one hand, their attempts at entering the electric car market have been unsuccessful thus far. On the other hand, retreating from the emerging industry may be detrimental if gas-powered cars become vestigial in the future. Should GM simply continue to manufacture standard automobiles? Or should they invest further in electric vehicles, acquiring the necessary technology to compete with market leaders?
\end{abstract}

Keywords: Market Entry; Automobile Industry; Electric Automobiles

\section{INTRODUCTION}

$\mathrm{t}$ is 2013. A tense boardroom convenes at the General Motors headquarters in Detroit, Michigan. The
anxious board looks on at Daniel Akerson, CEO and Chairman of General Motors, sitting pensively at
the end of the table. The agenda: managing the threat of the emerging electric car industry.

GM's foray into the electric vehicle market in 2010 with the hybrid Chevrolet Volt fell short of expectations as other manufacturers produced electric vehicles that had longer ranges, shorter recharging times, lower prices, and better all-around performance. Since then, weak demand for the Volt has forced GM to lower the Volt's price substantially, reducing firm profits. With updated electric vehicle models from other manufacturers entering the market and the development of battery technology, the board is considering several options. Many believe that GM should remain a manufacturer of combustible-engine automobiles. Others believe that the future of the automobile market lies with efficient and environmentally friendly electric vehicles. Pursuing electric vehicles with a renewed interest by acquiring new technology in order to compete with competitors' automobiles also poses significant issues. GM could develop the technology internally, acquire it directly from a competitor, or license it from another manufacturer. With or without the greater focus on electric vehicles, GM will have to find a way to deal with the emergence of electric vehicles and do so in the midst of sliding Volt sales, burgeoning demand for the competition's vehicles and slow economic growth.

\section{HISTORY OF THE ELECTRIC CAR}

GM was not the first manufacturer to produce electric vehicles. Since the early 1800 s, several inventors tried building small-scale automobiles powered by electric motors, although the first prototypes were not produced until 1891. Although A. L. Ryker and William Morrison built an electric six-passenger wagon in 1891, and interest in electric vehicles increased greatly in the late 1890s and early 1900s. This interest dissolved in the 1930s, largely due to the Great Depression. During this period, battery costs to produce electric cars were high, while gasoline prices were significantly lower than in previous years, making the research and development of electric vehicles less desirable for manufacturers (Bellis, 2013). 
It was not until 1990 that perceptions about electric vehicle development changed. With increased awareness of environmental issues, such as greenhouse gases and rising gasoline prices, several pieces of legislation were implemented in order to stimulate research and development in alternatives to gasoline-powered. For instance, the Clean Air Act Amendment, the U.S. 1992 Energy Policy Act, and regulations issued by the California Air Resources Board (CARB) provided supply side incentives for research and development by the private sector. Tightened air emission requirements and gasoline use regulations, as well as zero emission vehicle requirements further contributed to the renewed interest in non-gasoline vehicles (Bellis, 2013).

As a response to the increasing demand for alternative gas, the "Big Three" automobile manufacturers, in conjunction with the U.S. Department of Energy, created the Partnership for a New Generation of Vehicles (PNGV), a coalition aimed at structuring policy to provide incentives for electric car production. Shortly after, the first modern electric car was built by U.S. Electricar. An adapted Chevrolet S-10 pickup truck, the car used a dual alternating current motor and lead acid battery for power, and had a range of approximately 60 miles with a recharge time of seven hours. The car represented the first step in the modern electric car revolution.

\section{CURRENT STATE OF THE INDUSTRY}

Throughout the 2000s, economies of scale, battery improvements, and tax credits helped reduce the price and improve the quality of electric and hybrid vehicles (Bellis, 2013). In the past five years especially, the hybrid and electric vehicle manufacturing industry has seen strong growth driven by high oil prices, increased consumer tax credits, improved consumer confidence, and rising environmental awareness. ${ }^{1}$ In comparison, gas-powered vehicle manufacturing did not see such growth. ${ }^{2}$ Future expectations indicate even stronger growth ${ }^{3}$ as booming populations in emerging economies and overall stability in the global economy are expected to keep oil prices high. While federal tax credits and incentives relating to purchasing hybrid or electric vehicles are expected to drop, falling battery costs may offset the slight increase in the net price to the consumer. Coupled with positive public perceptions of buying efficient and environmentally friendly automobiles, industry experts predict consumers will purchase more electric and hybrid vehicles in order to minimize fuel expenses.

Several issues continue to encumber the adoption of electric vehicles. First, long charging times present a significant obstacle (Molavi, 2011). Currently, most electric vehicles require several hours to charge their batteries completely. Those models that do not require this amount of time have the most expensive batteries, and therefore the highest final prices. In general, electric cars continue to be more expensive than gasoline-powered cars. The average gas-powered 4-door sedan costs, on average, $\$ 12,000$ less than electric vehicles (Shetty, 2013). In addition, the necessary infrastructure of charging stations is not yet well-developed. While Tesla developed a charging infrastructure ecosystem called "Supercharger Stations," these stations remain located only within metropolitan areas.

\section{TECHNOLOGICAL DEVELOPMENT}

\section{Battery Commoditization}

Fiscal challenges to the mass production of electric vehicles are expected to improve. Currently, the most expensive part of an electric vehicle is the lithium-ion battery. While batteries remain the most significant input in production, and the most costly to develop, the cost of the standard electric battery has dropped nearly 50\% over the last four years and is expected to continue to fall 7.5\% CAGR until 2020. The U.S. Department of Energy predicts the cost of an electric vehicle battery will drop to $\$ 10,000$ by 2015 (Hall, 2013).

\section{Lithium-Ion Battery Alternatives}

While lithium-ion batteries currently power all electric models, researchers at Stanford University have developed a zinc-air battery that has a higher catalytic activity and durability than lithium-ion batteries. A study in

\footnotetext{
${ }^{1}$ Annualized growth rate of $2.5 \%$ between 2008 and 2013 (Molavi, 2011)

${ }^{2}$ Annualized growth rate of $1.9 \%$ between 2008 and 2013 (Molavi, 2011)

${ }^{3}$ Expectations of annualized growth in the hybrid and electric car industry are about 6.3\% through 2016 to $\$ 4.2$ billion (Molavi, 2011).
} 
Engineer Magazine shows that "Zinc-air batteries are attractive because of the abundance and low cost of zinc metal, as well as the non-flammable nature of aqueous electrolytes, which make the batteries inherently safe to operate" (The Engineer, 2013). While shortcomings of the zinc battery include finding efficient and robust air catalysts, preliminary results from using non-precious metal oxide electrocatalysts are promising.

In addition to the zinc alternative, Stanford University researchers have also developed a potassium battery which retains its charge better and longer than lithium-ion batteries. Researchers claim that the potassium battery can retain $83 \%$ of its charge after 40,000 cycles, while the lithium-ion battery retains the same amount of charge after only 10,000 cycles (Johnson, 2011). While the weight of the battery is considerably heavier than lithium-ion batteries, making it unlikely to be integrated into vehicles yet, future developments could make the battery lighter and therefore contend with lithium-ion batteries.

Magnesium batteries are also a viable alternative to lithium-ion batteries. Pellion Technologies, a technology firm dedicated to the rapid commercialization of magnesium ion batteries, seeks to develop the world's eighth most abundant element to produce batteries with higher energy capacities. As Josh Nevin, Pellion's VP of Operations and Business Development, explains, "Because magnesium-ions transfer two electrons per atom...you get twice the energy density right off the bat. The other key is the magnesium metal anode [which] provides much higher energy density than conventional lithium-ion anodes. The net result is a battery with up to three times the energy density of state-of the-art lithium-ion batteries" (Cohen, 2011). The battery will also have a longer cycle than today's lithium-ion battery because magnesium discharges less during the anode cycle. Magnesium is less expensive when compared to lithium and is a more stable element in its base state, making production of magnesium a safer process (Cohen, 2011).

\section{THE CHEVROLET VOLT}

General Motors announced the introduction of the Chevrolet Volt at the North American International Auto Show in 2007. The concept car had the capability of accelerating from 0 to $60 \mathrm{mph}$ in 9.3 seconds and reaching a speed of $100 \mathrm{mph}$. A $16 \mathrm{kWh}$ lithium-ion battery pack powered an engine that could generate $236 \mathrm{lb}$-ft of torque (Rafinejad, 2013). The Volt also featured a 12-gallon gasoline tank which could, in turn, provide an additional 600 miles to the automobile's range, with an estimated 50 miles per gallon efficiency.

The production model of the Chevrolet Volt was unveiled in September 2008. The production of its design differed significantly from the initial concept, with several cosmetic and technological changes. Chevrolet scaled back the size of the gas tank to 10 gallons and final estimates for the car's all electric range was 35 miles. The Volt featured a lithium manganese oxide cell battery produced by LG Chemical.

In 2010, Chevrolet began mass production of the Volt. The total cost to consumers of the Volt was approximately $\$ 33,000$, including a substantial federal tax credit. General Motors planned for initial production and sales estimates of 16,000 and 45,000 cars for 2011 and 2012, respectively (Rafinejad, 2013). Even though the Volt had won several environmental design awards, ${ }^{4}$ sales fell 2,000 units short of consumption estimates in 2011 and nearly 21,000 units in 2012, even though GM has recently decreased both the MSRP and lease prices substantially. Simultaneously, competitors to the Volt, such as the Nissan Leaf, have experienced sales booms ${ }^{5}$ (Woodyard, 2013).

\section{COMPETITORS}

\section{Tesla Motors, Inc.}

Tesla's Model S has emerged as one of the frontrunners in the electric car industry. The Model S, a fourdoor luxury sedan, was unveiled at a press conference on June 30, 2008 by Tesla Motors while full-scale production of the Model S did not begin until June 22, 2012. The Model S ranges in price from $\$ 58,570$ to $\$ 81,070$, prior to the $\$ 7,500$ tax credit (Tesla, 2013).

\footnotetext{
${ }^{4} 2009$ Green Car Vision Award, 2011 Green Car of the Year, 2011 North American Car of the Year, 2011 World Green Car and 2012 European Car of the Year (Rafinejad, 2013)

${ }^{5}$ Nissan's Leaf sales have increased by 371.9\% between 2013 Q2 and Q3 (Woodyard, 2013).
} 
The Model S has received several awards and accolades for innovative design and technology. The range of the $40 \mathrm{kWh}, 60 \mathrm{kWh}$, and $85 \mathrm{kWh}$ models vary from 140 to 300 miles, which outstrips the electric range of any competitor vehicle. The efficiency of the Model $\mathrm{S}$ is attributed to the quality and placement of the battery pack which is situated under the floor of a stiff, all-aluminum chassis that improves torsional rigidity and lowers the car's center of gravity, allowing for tighter handling, less drag, and greater speeds. The sedan accelerates from 0 to 60 $\mathrm{mph}$ in 5.6 seconds and can achieve a maximum speed of $125 \mathrm{mph}$. The Model S' real-mounted electric motor delivers 362 horsepower and $325 \mathrm{lb}$-ft of torque (Tesla, 2013).

In addition to its performance and efficiency, the Model S has also received several safety awards. The high level of safety is attributed to the design of the stiff aluminum chassis and the lack of an engine block in the front of car, which creates a longer crumpling time and less damage during high speed collisions. Also, since the automobile does not have a gas tank, the chances of fire and explosion are drastically reduced. The low center of gravity, which creates a stable platform, and double octagon extrusions in the front and rear further add to the safety features (Tesla, 2013). As a result of this design, the National Highway Traffic Safety Administration (NHTSA) has given the Model S the highest safety rating of any car on the market, with a 5-star overall safety rating and 5-star rating in every sub-category. Eleven judges unanimously voted the Model S the 2013 Motor Trend Car of the Year (MotorTrend, 2013). The Model S also received the highest score ever awarded - a 99 out of 100 - by Consumer Reports. In the report, the Consumer Reports analysts wrote: "[The Model S]... is brimming with innovation, delivers world-class performance, and is interwoven throughout with impressive attention to detail" (Consumer Reports, 2013).

\section{Nissan Motor Company, Ltd.}

Nissan has been the domestic and international market leader in electric vehicle sales since the introduction of the Nissan Leaf in 2010. Nissan began its foray into the electric vehicle market in 1997 with the Nissan Altra but did not achieve renowned success until the introduction of the Leaf. The Nissan Leaf is manufactured in Japan and the United States but is sold in over twenty international markets, with a majority of its sales coming from the US, Japan, and Europe. In addition, manufacturing in England and China began in March 2013 as a response to increased demand for the leaf in European and Asia markets, respectively. As of September 2013, Nissan has sold over 83,000 Leafs worldwide (Nissan, 2013).

The world's best-selling electric vehicle has a 75 -mile range on a four-hour charge. The $\$ 28,800$ five-door hatchback's $24 \mathrm{kWh}$ lithium-ion battery powers an $80 \mathrm{~kW}$ electric motor that can produce 110 horsepower and 210 $\mathrm{lb}$-ft of torque. The Leaf accelerates from 0 to $60 \mathrm{mph}$ in 9.8 seconds and has a top speed of $93 \mathrm{mph}$. In addition, the battery is expected to retain $70 \%$ to $80 \%$ of its capacity after 10 years. The Leaf can be charged quickly with a home charging station installed by Nissan or a car modification that allows for 120 or 240 volt charging using a standard DC outlet. As a result of its design and performance, the Nissan Leaf won the 2010 Green Car Vision Award, the 2011 European Car of the Year, the 2011 World Car of the Year, and the 2011 and 2012 Japanese Car of the Year (Nissan, 2013).

\section{Other Manufacturers}

Other competitors are interested in establishing a presence in the alternative fuel market. In Europe, for instance, Bayerische Motoren Werke (BMW) began mass production of the two-door electric i3 in September 2013. Due to low hydroelectric energy costs in the US, BMW ships raw carbon from Japan to the US in order to produce the carbon-fiber reinforced bodywork of the i3. Final fabrication of the carbon-fiber parts and assembly occurs at the BMW Leipzig plant in Germany. Initial target markets include the United States and major European countries such as Germany, UK, France, Netherlands, and Norway. Deliveries are slated to take place in late 2013 (BMW, 2013).

The i3 costs $\$ 41,350$ but has a maximum range of 120 miles in its most efficient mode on a three-hour charge. The i3 also has a "range extender" (REx) option, which incorporates a two-cylinder combustible engine with a 2.4-gallon tank and adds about seventy miles to the car's range. The large range is due to a carbon-fiber-reinforced plastic body and different driving modes with energy-saving settings. The i3 also has a fast charge option that allows the car to be charged in thirty minutes at a public DC charging station. The $18.8 \mathrm{kWh}$ lithium-ion battery powers the 
170 horsepower electric motor which can achieve a max torque of 250 according to the $\$ 54.9$ auto manufacturer (BMW, 2013).

Ford is another domestic automobile manufacturer that produces an electric car model. Unveiled in 2011, the Ford Focus Electric is produced in Michigan, United States, for the domestic market. Ford began international production for European markets in Germany in August 2013. As of September 2013, over 2,000 Focus Electrics have been sold in the United States (Ford, 2013).

The $2013 \$ 39,200$ Ford Focus Electric has a range of 76 miles on a four-hour charge. The five-door hatchback is powered by a liquid-cooled $23 \mathrm{kWh}$ lithium ion battery. The 143 horsepower motor can generate 184 $\mathrm{lb}$-ft of torque. The $\$ 69.4$ billion manufacturer claims the Focus Electric can accelerate from 0 to 60 miles per hour in approximately 9.5 seconds and achieve a top speed of 84 miles per hour (Ford, 2013).

\section{CONCLUSION}

As the board discussed the electric vehicle environment at GM's headquarters, it seemed that competition was only intensifying. Other manufacturers were lowering the costs and improving the range of their electric automobiles as they spoke. Researchers and scientists across the countries were developing more efficient low-cost batteries. Developing the technology internally would be capital intensive and may not yield a competitive technology, but would ensure that GM possessed a technology that other firms do not. Acquiring the technology from another firm would save time and lower development obstacles but may be costly and incongruous with GM's vehicles. Licensing the technology would lower the initial capital required for investment but could lead to high future transaction costs and dependency. With increased shareholder pressure, the board's time to make a decision was dwindling. On the precipice of major industry change, GM needed to make a decision or risk getting left behind.

\section{AUTHOR INFORMATION}

Sharon L. Poczter is an Assistant Professor of managerial economics in the Charles H. Dyson School of Applied Economics and Management at Cornell University. Her research examines the impact of government policy on firm level financial outcomes. E-mail: sharon.poczter@ cornell.edu (Corresponding author)

Luka M. Jankovic is an undergraduate student in the Charles H. Dyson School of Applied Economics and Management at Cornell University. His primary interests are finance, investing, and strategy. E-mail: 1mj57@cornell.edu

\section{REFERENCES}

1. Abuelsamid, S. (2010, July 27). 2011 Chevrolet Volt priced at $\$ 41,000 *$ or $\$ 350 /$ month for three-year lease. Retrieved from http://www.autoblog.com/2010/07/27/2011-chevrolet-volt-priced-at-41-000-or-350month-for-3-year-lease/

2. Bellis, M. (2013). History of electric vehicles. Retrieved from http://inventors.about.com/od/estartinventions/a/History-Of-Electric-Vehicles.htm

3. BMW. (2013). Bmw i3 technical data. Retrieved from http://www.bmw.com/com/en/newvehicles/i/i3/2013/showroom/technical_data.html

4. Clean Technica. (2013). The electric car battery price slide. Retrieved from http://cleantechnica.com/2013/06/14/the-electric-car-price-slide-chart/

5. Cohen, Y. (2011, November 17). A magnesium battery? Khosla, arpa-e explore lithium alternative. Retrieved from http://www.greentechmedia.com/articles/read/a-magnesium-battery-khosla-arpa-e-explorelithium-alternative

6. $\quad$ Consumer Reports. (2013, June). Tesla model s review. Retrieved from http://www.consumerreports.org/cro/magazine/2013/07/tesla-model-s-review/index.htm

7. Ford. (2013). Ford focus electric. Retrieved from http://www.ford.com/cars/focus/specifications/viewall/?searchid=71062349|2746995869|19814177744\&ef_id=DfBQGVHBVG0AAFLF:20131022143356:s 
8. General Motors. (2013). General motors. Retrieved from http://www.gm.com/?seo=goo_|_GM+GM.com_|_AWR-GM+General-Exact_|_General+Motors++MSP_|_generalmotors

9. Hall, M. (2013, July 30). Electric vehicle battery costs falling. Retrieved from http://www.pvmagazine.com/news/details/beitrag/electric-vehicle-battery-costs-falling_100012196/

10. Johnson, D. (2011, November 25). New battery technology could provide large-scale energy storage for the grid. Retrieved from http://spectrum.ieee.org/nanoclast/semiconductors/nanotechnology/new-batterytechnology-could-provide-largescale-energy-storage-for-the-grid

11. Molavi, J. (2011). Hybrid \& electric vehicle manufacturing industry report. Retrieved from http://www.ibisworld.com/

12. Nissan. (2013). Nissan leaf. Retrieved from http://www.nissanusa.com/electric-cars/leaf/features/

13. Rafinejad, D. (2013). Chevrolet volt a disruptive innovation bridge to electrified transportation. Retrieved from http://www.nadaguides.com/Cars/2013/chevrolet/volt/Model-history

14. Shetty, S. (2013, July 5). Electric vehicles still struggling to be cost-competitive. Retrieved from http://tech.fortune.cnn.com/2013/07/05/electric-vehicles/

15. Tesla. (2013). Tesla motors. Retrieved from http://www.teslamotors.com/

16. The Engineer. (2013). Zinc-air battery could be low-cost alternative to lithium-ion. Retrieved from http://www.theengineer.co.uk/energy-and-environment/news/zinc-air-battery-could-be-low-costalternative-to-lithium-ion/1016408.article

17. Woodyard, C. (2013, August 6). Gm gives chevrolet volt a jolt with price cut. Retrieved from http://www.usatoday.com/story/money/cars/2013/08/06/gm-chevrolet-volt-price-cut/2621657/ 